\title{
$\beta$-Elemene enhances the efficacy of gefitinib on glioblastoma multiforme cells through the inhibition of the EGFR signaling pathway
}

\author{
LIN MU ${ }^{1,2}$, TIANJIAO WANG ${ }^{1}$, YANWEI CHEN ${ }^{1}$, XINQIANG TANG $^{1}$, YUHUI YUAN ${ }^{1}$ and YONGSHUN ZHAO $^{1}$ \\ ${ }^{1}$ The First Affiliated Hospital, Institute of Cancer Stem Cell, Dalian Medical University; \\ ${ }^{2}$ College of Pharmacy, Dalian Medical University, Dalian, Liaoning 116011, P.R. China
}

Received April 7, 2016; Accepted June 8, 2016

DOI: $10.3892 /$ ijo.2016.3626

\begin{abstract}
Glioblastoma multiforme (GBM) is the most common and severe form of primary tumor in the central nervous system of adults which has poor prognosis and limited therapeutic options. Epidermal growth factor receptor (EGFR) inhibitor, such as gefitinib (brand name Iressa, ZD1839), has been approved as a targeted medicine for several types of tumor including glioblastoma multiforme. However, gefitinib exerted very limited effects on some glioblastoma multiforme patients after a period of treatment due to intrinsic and acquired drug resistance. $\beta$-Elemene, a natural plant drug extracted from Curcuma wenyujin, has shown promising anticancer effects against a broad spectrum of tumors. In the present study, we found that $\beta$-elemene could enhance the chemosensitivity of glioblastoma multiforme cells to gefitinib. The combination medication of $\beta$-elemene and gefitinib not only inhibited the survival and proliferation of glioblastoma multiforme cells via inhibition of EGFR signaling pathway but also induced more distinct apoptosis and autophagy in the glioblastoma multiforme cells than the gefitinib monotherapy. These results showed that $\beta$-elemene might be one potential adjuvant to enhance the effect of EGFR inhibitor and reduce the resistance of gefitinib in glioblastoma multiforme.
\end{abstract}

Correspondence to: Dr Yongshun Zhao or Professor Yuhui Yuan, The First Affiliated Hospital, Institute of Cancer Stem Cell, Dalian Medical University, 9 West Section of Lushun South Road, Dalian, Liaoning 116044, P.R. China

E-mail: zhaoyongshun_2005@aliyun.com

E-mail: yuhuiyuan@hotmail.com; yuhuiyuan@dlmedu.edu.cn

Abbreviations: GBM, glioblastoma multiforme; EGFR, epidermal growth factor receptor; MAPK, mitogen-activated protein kinase; $\mathrm{BBB}$, blood-brain barrier; TMZ, temozolomide

Key words: glioblastoma multiforme, $\beta$-elemene, gefitinib, epidermal growth factor receptor pathway, chemosensitivity

\section{Introduction}

Glioblastoma multiforme (GBM) is the most frequently occurring malignant intracranial tumor in adults, with aggressive, invasive, angiogenic and destructive features. It is recognized as diffuse astrocytoma grade IV by the World Health Organization $(1,2)$. GBM accounts for $12-15 \%$ of all primary brain tumors and 50-60\% of all astrocytic tumors (3). Despite the wide range of GBM treatments, including surgery, radiotherapy, and chemotherapy, less than $10 \%$ of patients survive over 3 years after the diagnosis $(4,5)$. Thus, effective therapeutic interventions are urgently needed to improve the poor prognosis of GBM.

As one of the four members of the ErbB family, epidermal growth factor receptor (EGFR) tyrosine kinase has been identified as an important factor for cancer cell growth, proliferation, invasion and metastasis (6-8). It is reported that EGFR gene is generally amplified and/or overexpressed in high-grade glioblastoma multiforme, with a frequency of approximately 50\% (9). Gefitinib, a specific small molecule inhibitor of EGFR, has been shown to exert therapeutic effect on these highly aggressive brain tumors via inhibiting proliferation and inducing apoptosis of tumor cells in human glioblastoma multiforme $(10,11)$. However, multiple studies have demonstrated that as a single agent for the therapy of human glioblastoma multiforme, gefitinib is limited due to its frequent drug resistance and the serious cytotoxicity in clinical trials (12-15).

$\beta$-Elemene (1-methyl-1-vinyl-2,4-diisopropenylcyclohexane), a novel anticancer agent, is the major active component extracted from the traditional Chinese medicinal plant Curcuma wenyujin. It has been shown to be effective against a variety of tumors in vitro and in vivo such as lung carcinoma, breast, leukemia, ovarian cancer and glioblastoma multiforme (16-20). The significant effect of $\beta$-elemene is mainly caused by its ability to pass through the blood-brain barrier (BBB) and reverse the resistance of glioblastoma multiforme to other drugs such as cisplatin $(21,22)$. In addition, the specific mechanism could be inhibiting the growth and DNA synthesis of multiple types of tumor cells, which result in the apoptosis or suppressed growth of tumor without severe side-effects $(23,24)$. 
Moreover, our previous studies have demonstrated that $\beta$-elemene inhibited the growth of GBM cells through a p38 MAPK-dependent signaling pathway (20), deactivated the Raf/ MEK/ERK pathway in GBM cells by impairing formation of the Hsp90/Raf-1 complex (25), and significantly inhibited the repair of DNA damage in GBM cells in combination with radiation or temozolomide (TMZ) via interfering with the ATM, AKT and ERK signaling pathways (26).

In the present study, we found that $\beta$-elemene has a sensitization effect on gefitinib in human GBM cells with low toxicity and few side-effects. $\beta$-Elemene enhanced the inhibition of proliferation and survival of GBM cells through the EGFR signaling pathway, affected the activities of downstream related proteins AKT and ERK. In addition, the combination of $\beta$-elemene and gefitinib enhanced apoptosis and autophagy in GBM cells compared with gefitinib monotherapy. These results suggested that $\beta$-elemene might be considered as a valuable agent to enhance the chemotherapy effect during glioblastoma multiforme treatment. The synergistic therapy of $\beta$-elemene and gefitinib shows potential as a new therapeutic strategy against human glioblastoma multiforme.

\section{Materials and methods}

Cell lines and culture. The human glioblastoma multiform cell lines U251, U87-MG were purchased from the American Type Culture Collection (ATCC; Manassas, VA, USA). These cells were cultured in Dulbecco's modified Eagle's medium (DMEM; Gibco, Carlsbad, CA, USA) with $10 \%$ fetal bovine serum (FBS; Gibco), 100 units/ml of penicillin and $100 \mu \mathrm{g} /$ $\mathrm{ml}$ streptomycin, and incubated at $37^{\circ} \mathrm{C}$ in a humidified atmosphere with $5 \% \mathrm{CO}_{2}$.

Reagents and antibodies. $\beta$-Elemene (99.2\% purity) which was obtained from the National Institutes for Food and Drug Control (NIFDC; Beijing, China) was dissolved in dimethyl sulfoxide (DMSO; Sigma-Aldrich, St. Louis, MO, USA) at $20 \mathrm{mg} / \mathrm{ml}$ as a stock solution. Gefitinib was purchased from Selleck Chemicals (Houston, TX, USA) and dissolved in DMSO at $100 \mathrm{mM}$ as a stock solution. The antibodies against EGFR, phospho-EGFR (Tyr1068), AKT, phospho-AKT (ser473), ERK, phospho-ERK, PARP, Cleaved PARP (Asp214), caspase-3, cleaved caspase-3, LC-3, Beclin1, Atg5, Atg16L and GAPDH were purchased from Cell Signaling Technology (Danvers, MA, USA). Anti-rabbit as the secondary antibody also was purchased from Cell Signaling Technology.

Cell viability assay. The viability of the cells was detected using the 3-(4,5-dimethylthiazol-2-yl)-2,5-diphenyltetrazolium bromide (MTT) assay. Human glioblastoma multiform cell lines U251 and U87-MG were seeded at a density of $6 \times 10^{3}$ cells/well in 96-well plates, respectively, incubated overnight and exposed to the indicated concentrations of gefitinib $(30 \mu \mathrm{M})$ and $\beta$-elemene $(40 \mu \mathrm{g} / \mathrm{ml})$ for $24 \mathrm{~h}$. Thereafter, $10 \mu \mathrm{l}$ of MTT solution $(5 \mathrm{mg} / \mathrm{ml})$ was added to each well before the GBM cells were incubated for another $4 \mathrm{~h}$ at $37^{\circ} \mathrm{C}$. After removal of the culture medium, the GBM cells were lysed in $150 \mu \mathrm{l}$ of dimethyl sulfoxide (DMSO), and the optical density (OD) was measured at $490 \mathrm{~nm}$ with an absorbance reader
(Perkin-Elmer, Waltham, MA, USA). The concentration required to inhibit cell growth by $50 \%\left(\mathrm{IC}_{50}\right)$ was calculated from survival curves.

Colony formation assay. The proliferation ability of cells was detected by colony formation assay. Human glioblastoma multiform cell lines U251 and U87-MG were seeded in 6-well plates and counted at $1 \times 10^{3} /$ well supplemented with fresh medium cultured for $24 \mathrm{~h}$. Then, the GBM cells were exposed to indicated concentrations of gefitinib $(30 \mu \mathrm{M})$ and $\beta$-elemene $(40 \mu \mathrm{g} / \mathrm{ml})$ and incubated for an additional 15 days. To visualize and count cell colonies, the GBM cells were fixed and stained with crystal violet. Clusters of $>50$ cells were counted as a colony.

Western blot assay. The human glioblastoma multiform cell lines U251 and U87-MG were treated with gefitinib $(30 \mu \mathrm{M})$ and $\beta$-elemene $(40 \mu \mathrm{g} / \mathrm{ml})$ for $24 \mathrm{~h}$, then, extracted with the RIPA buffer added the proteinase inhibitor (PMSF, $1 \mathrm{mg} / \mathrm{ml}$ ) on ice which including $25 \mathrm{mM}$ Tris- $\mathrm{HCl}(\mathrm{pH} 7.6), 150 \mathrm{mM}$ Nacl, $1 \%$ Triton X-100, $1 \%$ sodium deoxycholate and $0.1 \%$ SDS. After centrifugation at $14,000 \times \mathrm{g}$ at $4^{\circ} \mathrm{C}$ for $20 \mathrm{~min}$, the protein concentration was determined by the BCA assay kit (Thermo Fisher Scientific, Waltham, MA, USA). The proteins resolved by $8-12 \%$ SDS-PAGE, transferred to polyvinylidene difluoride membrane (PVDF; Amersham) and blocked with $5 \%$ skim milk in TBST buffer $2 \mathrm{~h}$. The membranes were then incubated with specific primary antibodies overnight at $4^{\circ} \mathrm{C}$, followed by treatment with HRP-conjugated secondary antibodies. The protein bands were detected by ChemiDoc ${ }^{\mathrm{TM}}$ XRS+ imaging system (Bio-Rad Laboratories, Hercules, CA, USA).

Fluorescence microscopy. The human glioblastoma multiform cell line U251 was seeded in each well of 24-well plates with poly-L-lysine-coated coverslips and treated with gefitinib $(30 \mu \mathrm{M})$ and $\beta$-elemene $(40 \mu \mathrm{g} / \mathrm{ml})$ for $24 \mathrm{~h}$. Cells on coverslips were washed with phosphate-buffered saline (PBS) 3 times, fixed with $4 \%$ paraformaldehyde (PFA) solution in PBS at room temperature for $15 \mathrm{~min}$. After washing the samples with PBS 3 times, the cells were treated with $2 \%$ Triton X-100 5 min and blocked with $5 \%$ bovine serum albumin (BSA) for $30 \mathrm{~min}$. The slides were incubated with anti-LC3 antibody at a 1:100 for $30 \mathrm{~min}$ and then labeled with fluorescein isothiocyanate (FITC)-conjugated goat anti-rabbit IgG for $20 \mathrm{~min}$. The cells nuclei were stained with 4',6-diamidino-2-phenylindole (DAPI; Molecular Probes-Invitrogen), and immunofluorescent images were examined under a fluorescence microscope (Olympus, Tokyo, Japan).

Transmission electron microscopy. The human glioblastoma multiform cell line U87-MG was treated with gefitinib $(30 \mu \mathrm{M})$ and $\beta$-elemene $(40 \mu \mathrm{g} / \mathrm{ml})$ for $24 \mathrm{~h}$ before washed and collected by trypsinization. Then, the cells were fixed with $2.5 \%$ glutaraldehyde for $30 \mathrm{~min}$, post-fixed in $2 \%$ osmium tetroxide for $2 \mathrm{~h}$. Cells were then dehydrated by ethanol and polymerized by epoxy resin. Finally, the embedded, sectioned, double stained with uranyl acetate and lead citrate samples were analysed using a JEM-1200EX transmission electron microscope (JEOL, Tokyo, Japan). 


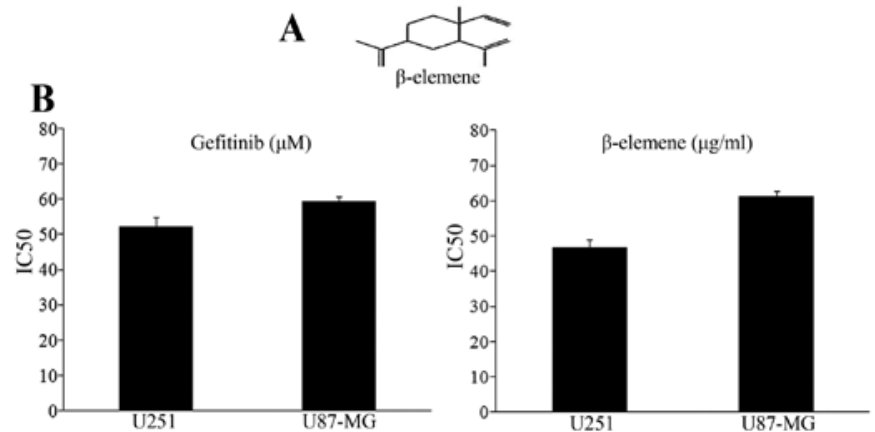

Figure 1. (A) Chemical structure of $\beta$-elemene. (B) The $\mathrm{IC}_{50}$ values of the human GBM cells U251 and U87-MG with the treatment of gefitinib and $\beta$-elemene respectively.

Statistical analysis. In the present study each experiment was performed at least three times. Statistical analysis was conducted by the Student's t-test and the group differences were considered significant at $\mathrm{P}<0.05$. The analysis were performed by SPSS 13.0 software.
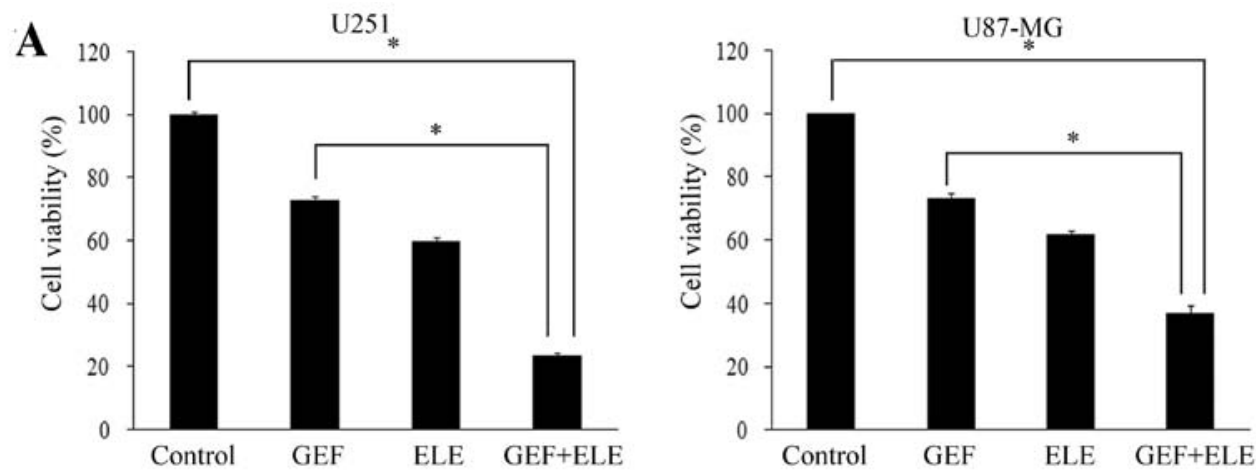

B
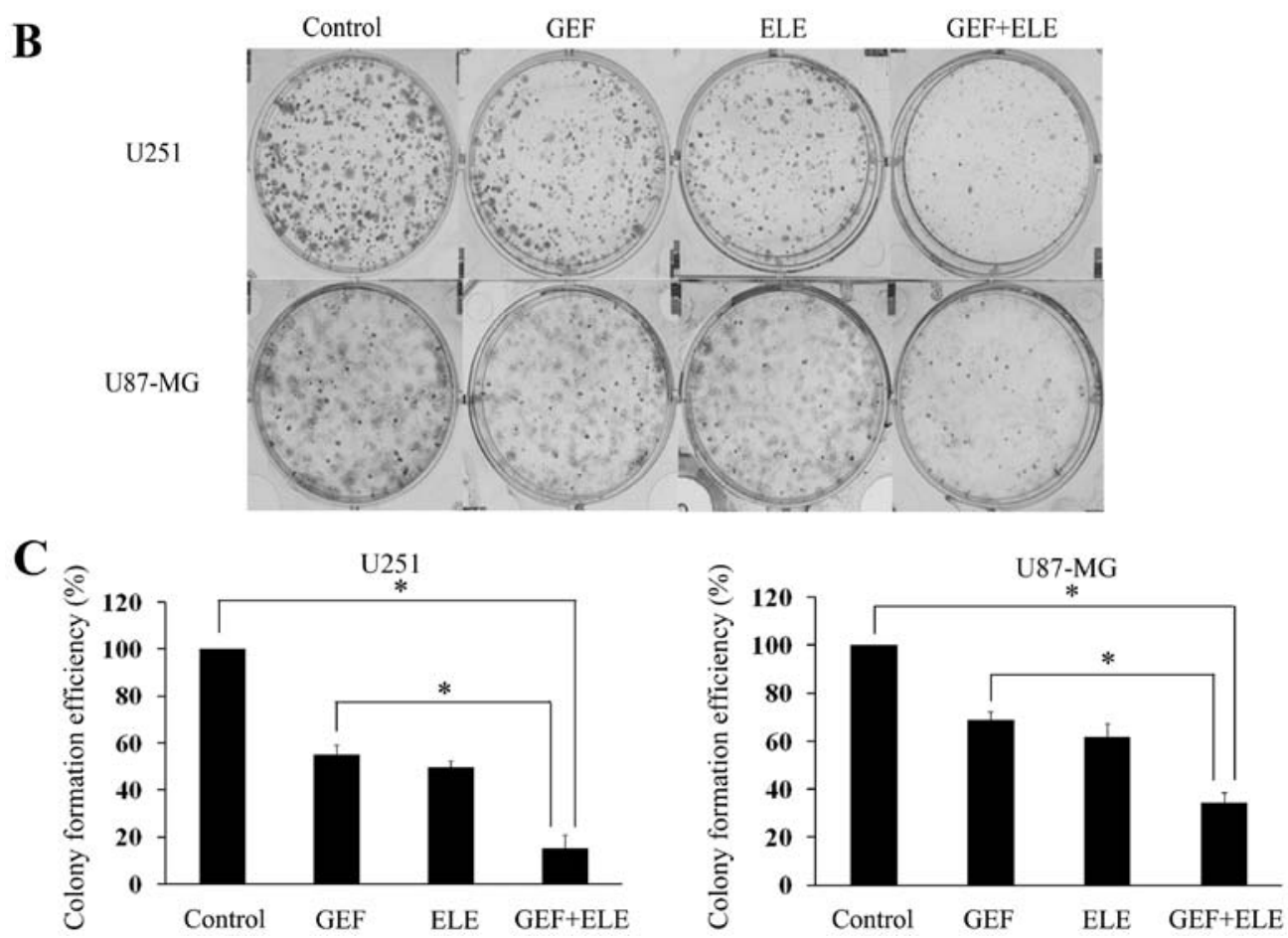

Figure 2. $\beta$-elemene increases the inhibitory effect of gefitinib on survival and proliferation of GBM cells. (A) Cell viability was measured after treated by indicated concentrations of gefitinib and $\beta$-elemene for $24 \mathrm{~h}$. (B) The proliferation of cells was measured by colony formation assay. (C) The quantification of colony formation. The results are representatives of three independent experiments. ${ }^{*} \mathrm{P}<0.05$ compared with untreated control group.
$\beta$-Elemene increases the inhibitory effects of gefitinib on the proliferation and survival of GBM cells. The structure of $\beta$-elemene is shown in Fig. 1A, and the value of median inhibitory concentration $\left(\mathrm{IC}_{50}\right)$ in human glioblastoma multiforme cell lines was calculated by the growth inhibition curves shown in Fig. 1B. The $\mathrm{IC}_{50}$ doses for gefitinib at $52.24 \mu \mathrm{M}$ for $\mathrm{U} 251$ and $59.38 \mu \mathrm{M}$ for U87-MG. The $\mathrm{IC}_{50}$ value for $\beta$-elemene is $46.72 \mu \mathrm{g} / \mathrm{ml}$ for $\mathrm{U} 251$ and $61.33 \mu \mathrm{g} / \mathrm{ml}$ for U87-MG. By using the MTT assay, we tested the effects of gefitinib alone, $\beta$-elemene alone or combination on proliferation of glioblastoma multiforme cells. After treatment with either $30 \mu \mathrm{M}$ gefitinib, $40 \mu \mathrm{g} / \mathrm{ml} \beta$-elemene, or combination of these two drugs for $24 \mathrm{~h}$, the viability of cells demonstrated that $\beta$-elemene markedly increased the gefitinib-induced inhibition of cell growth in both U251 and U87-MG cells (Fig. 2A). For the colony formation assay, after the treatment with indicated concentrations of gefitinib and $\beta$-elemene for 15 days, the numbers of the colonies were fewer and the sizes were smaller in the combination treatment group when compared with the 
A

B

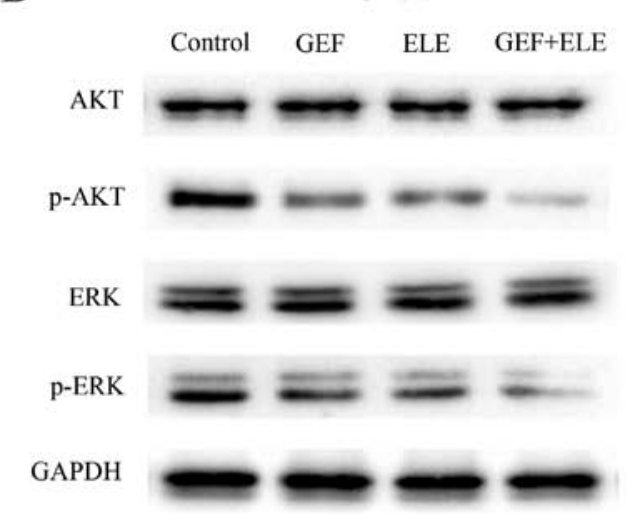

C

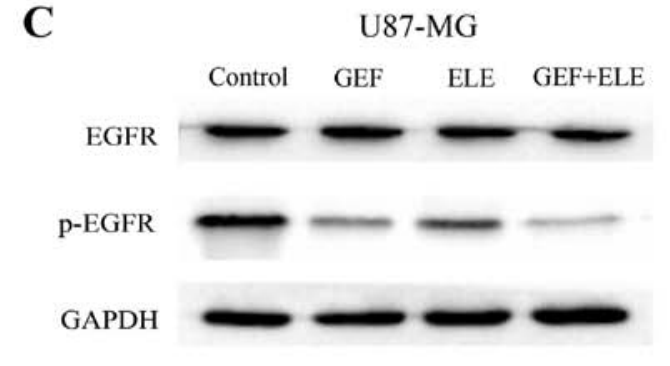

D

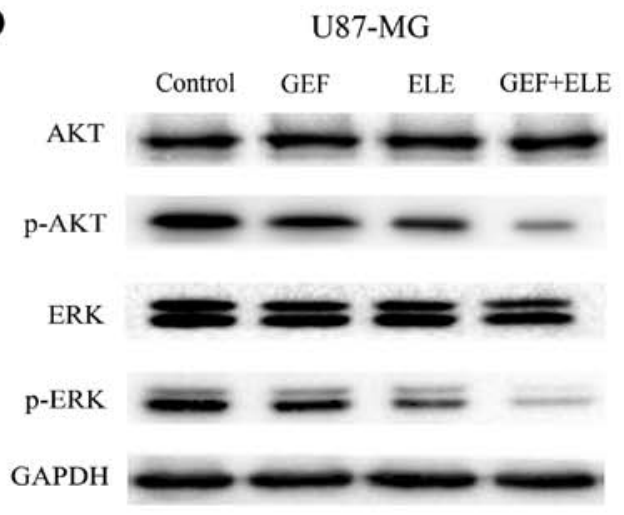

U251

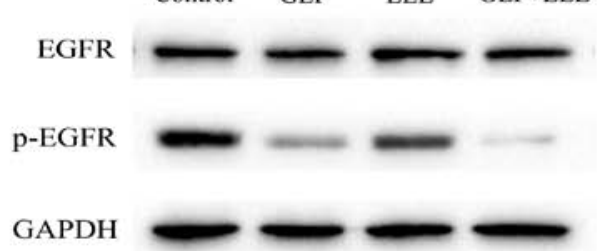

$\mathrm{U} 251$

GAPDH
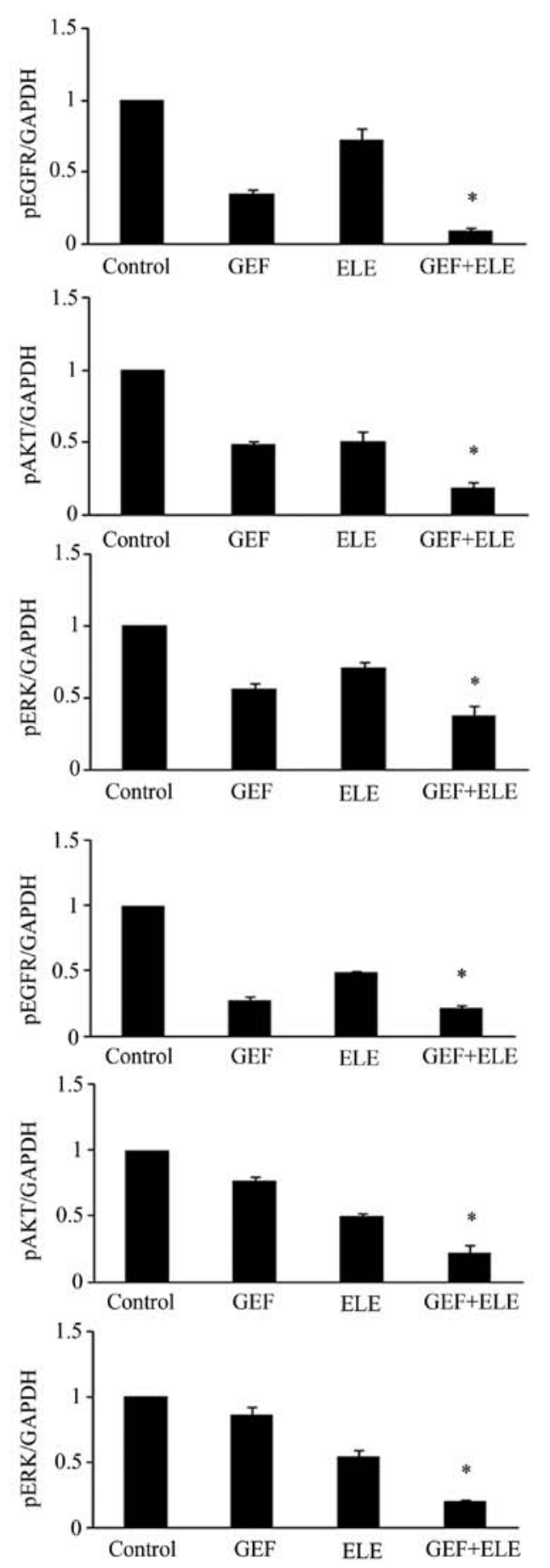

Figure 3. $\beta$-Elemene enhances the anti-proliferation ability of gefitinib on GBM cells through the inhibition of the EGFR signaling pathway. The human GBM cells U251 and U87-MG were treated with indicated concentrations of gefitinib alone, $\beta$-elemene alone or both for $24 \mathrm{~h}$. (A and C) The level of total and phosphorylated (p) EGFR, (B and D) AKT and ERK were examined by western blot analysis. GAPDH was used as a loading control. The levels of p-EGFR, p-AKT and p-ERK were corrected for GAPDH. The results are representatives of three independent experiments. "P<0.05, group treated with $\beta$-elemene vs. untreated group.

group treated with gefitinib alone or the control (Fig. 2B). Quantification of colony formation is shown in Fig. 2C. It was further confirmed that $\beta$-elemene enhanced the efficacy of gefitinib on inhibiting cell viability and proliferation in human glioblastoma multiforme cell lines U251 and U87-MG.

$\beta$-Elemene enhances the sensitivity of GBM cells to gefitinib via downregulating the activation of EGFR, AKT and ERK signalin. Human GBM cell lines U251 and U87-MG were treated with either $30 \mu \mathrm{M}$ gefitinib or $40 \mu \mathrm{g} / \mathrm{ml} \beta$-elemene, or co-treatment for $24 \mathrm{~h}$. Western blot analysis showed that although gefitinib played a significant role in the expression of p-EGFR protein levels, combination of gefitinib and $\beta$-elemene can suppress the activation of p-EGFR more obviously (Fig. 3A and C). We tested the downstream EGFR signaling pathways that mediated the effect of $\beta$-elemene and gefitinib on cell growth. We found that the combination of gefitinib and $\beta$-elemene group has more obvious effect on decreasing 
A

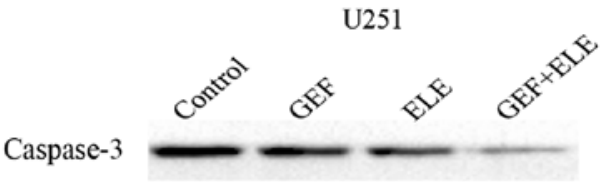

Cleaved caspase- 3

PARP

Cleaved PARP

GAPDH

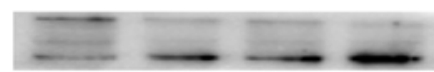

B
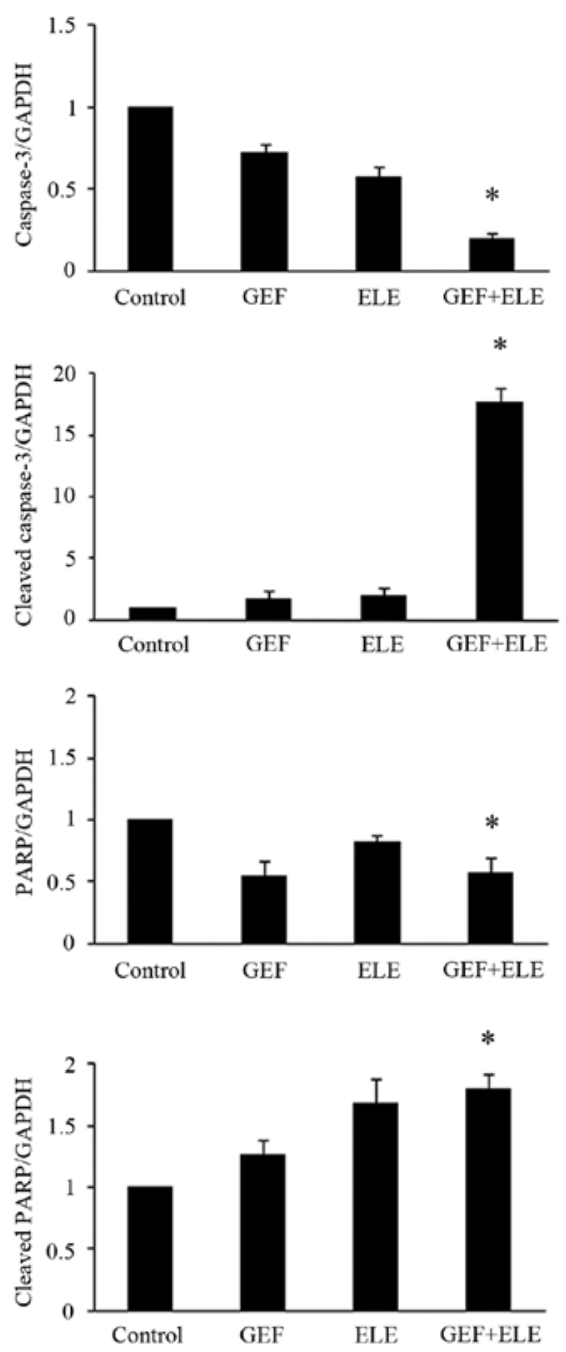

C

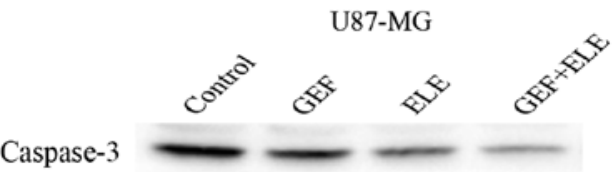

Cleaved caspase-3

PARP

Cleaved PARP

GAPDH

D
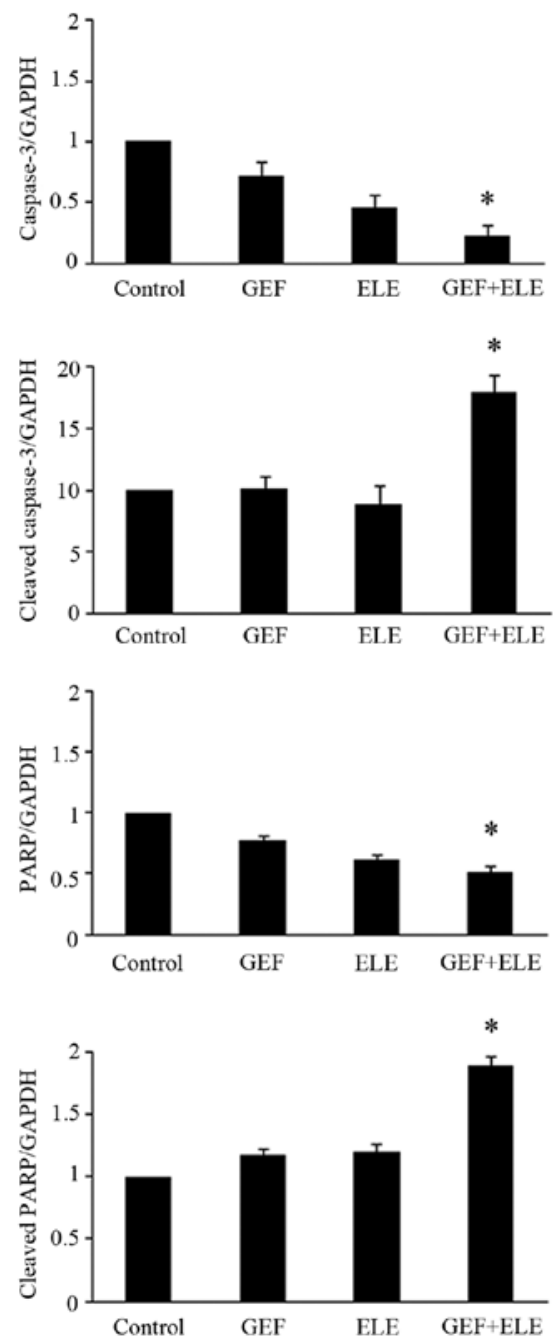

Figure 4. $\beta$-Elemene increases the ability of gefitinib to promote cell apoptosis in GBM cells. The human GBM cells U251 and U87-MG were treated with indicated concentrations of gefitinib alone, $\beta$-elemene alone or both for $24 \mathrm{~h}$, (A and C) the expression of apoptosis-related proteins caspase-3, cleaved caspase-3, PARP and cleaved PARP by immunoblotting. GAPDH was used as a loading control. (B and D) The levels of caspase-3, cleaved caspase-3, PARP and cleaved PARP were corrected for GAPDH. The results are representatives of three independent experiments. "P<0.05, group treated with $\beta$-elemene vs. untreated group.

the phosphorylation of AKT and ERK than the monotherapy group (Fig. 3B and D).

$\beta$-Elemene enhances the induction effects of gefitinib on the apoptosis of GBM cells. Human GBM cell lines U251 and U87-MG were treated with either $30 \mu \mathrm{M}$ gefitinib or $40 \mu \mathrm{g} / \mathrm{ml}$ $\beta$-elemene, or co-treatment for $24 \mathrm{~h}$. To analyze the synergistic effect of $\beta$-elemene and gefitinib in inducing cell apoptosis, we evaluated the activation of caspase- 3 and poly ADP-ribose polymerase (PARP) cleavage by western blot analysis (Fig. 4A and $\mathrm{C}$ ). The data indicated that the co-treatment of $\beta$-elemene and gefitinib caused significantly stronger caspase-3 and PARP cleavage than the single medication treatment (Fig. 4B and D).

$\beta$-Elemene increases the occurrence of autophagy induced by gefitinib in GBM cells. In addition to cell apoptosis research, we also examined the effect of $\beta$-elemene and gefitinib on inducing autophagy in GBM cells. Under the treatment of 

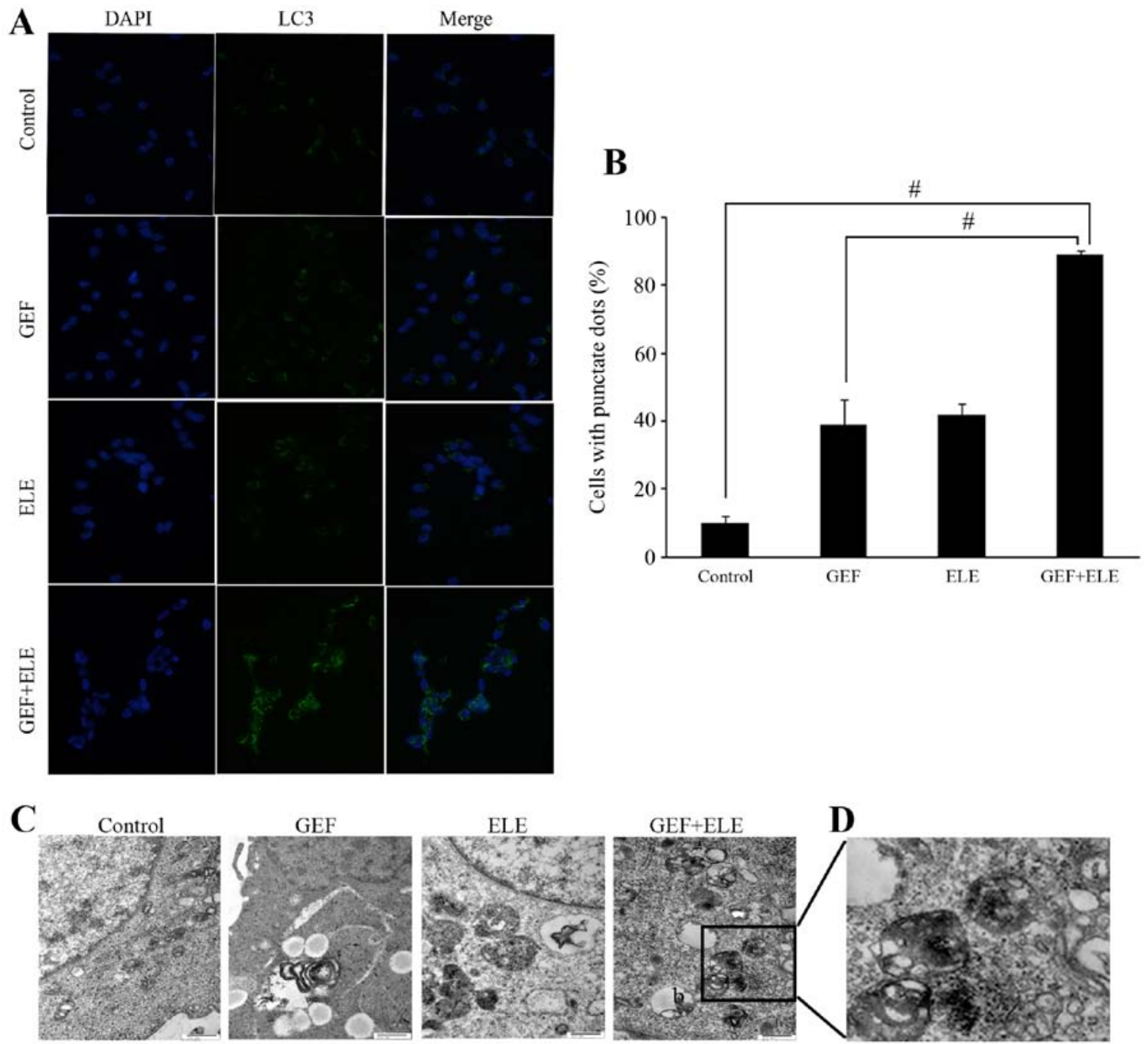

Figure 5. $\beta$-Elemene increases the occurrence of autophagy combined with gefitinib in human GBM cells. The human GBM cell lines U251 and U87-MG were treated with gefitinib $(30 \mu \mathrm{M})$ alone, $\beta$-elemene $(40 \mu \mathrm{g} / \mathrm{ml})$ alone or both for $24 \mathrm{~h},(\mathrm{~A}) \mathrm{U} 251$ cells stained and observed under a fluorescence microscope as described in Materials and methods. (B) The percentage of cells with punctuate dots is presented in the histogram. (C) U87-MG cells harvested and subjected to transmission electron microscopy as described in Materials and methods. (D) The square area including the structures identified as autophagosome and autolysosome. The results are representatives of three independent experiments. ${ }^{*} \mathrm{P}<0.01$ compared with untreated control group.

A

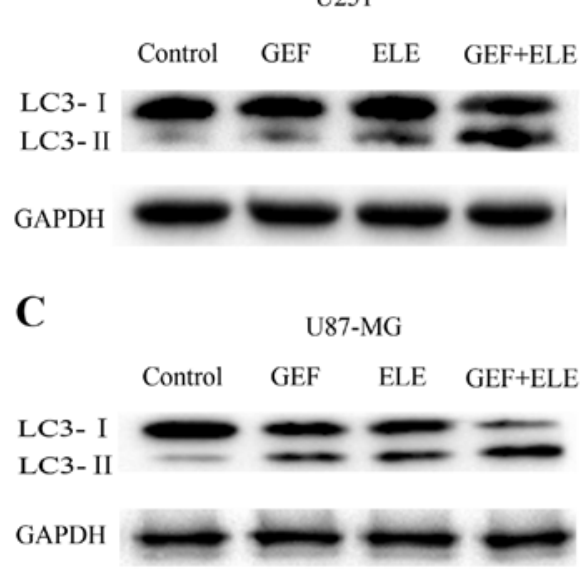

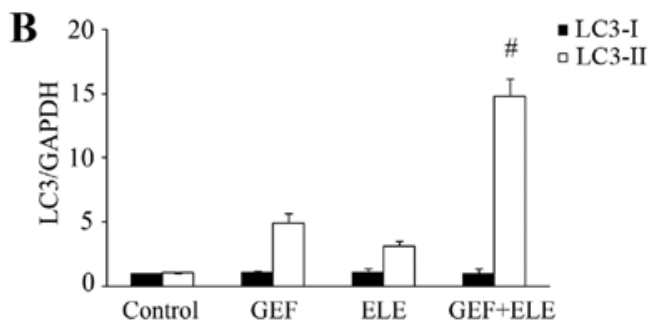

D

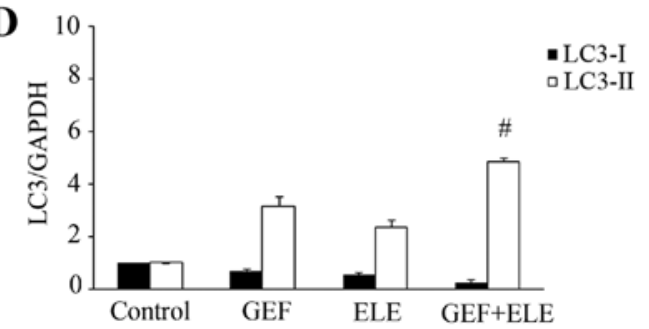

Figure 6. $\beta$-Elemene enhances sensitivity of gefitinib to induce autophagy of gefitinib in GBM cells. (A and C) The human GBM cell lines U251 and U87-MG were treated with gefitinib $(30 \mu \mathrm{M})$ alone, $\beta$-elemene $(40 \mu \mathrm{g} / \mathrm{ml})$ alone or both for $24 \mathrm{~h}$, and their lysates were subjected to western blotting with an anti-LC3 antibody. GAPDH was used as loading control. (B and D) The levels of LC3-Iand LC3-II were corrected for GAPDH. The results are representatives of three independent experiments. ${ }^{\#} \mathrm{P}<0.01$ compared with untreated control group. 
A

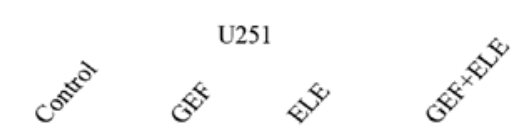

Becline 1

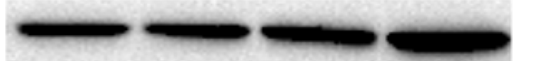

Atg 5

Atg 16L

GAPDH

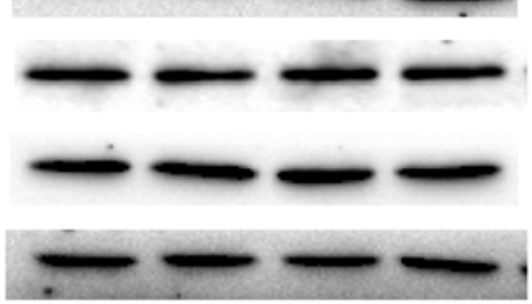

B
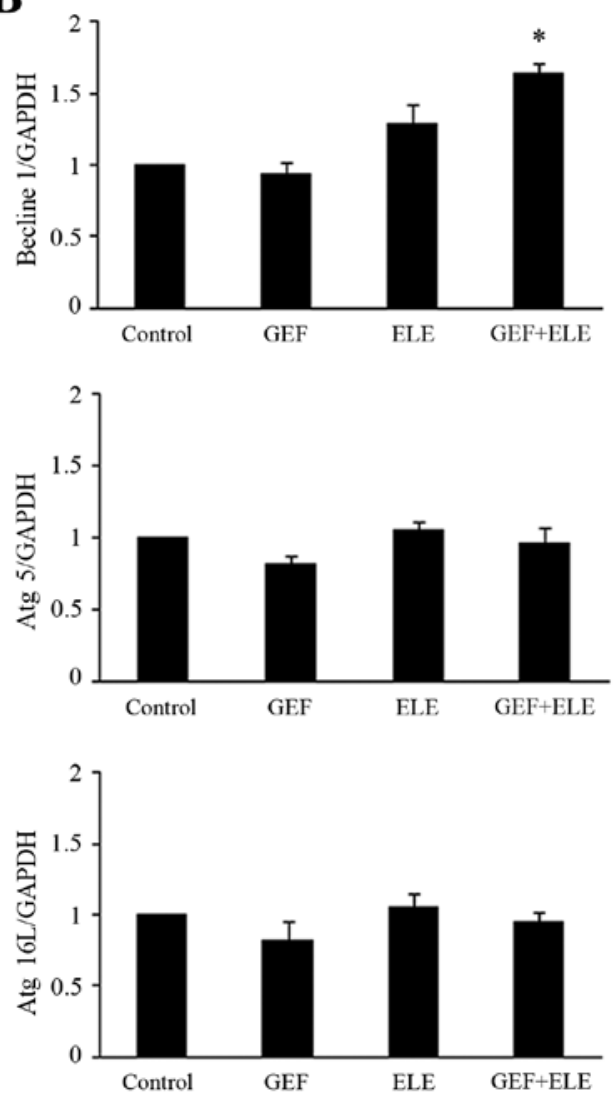

C
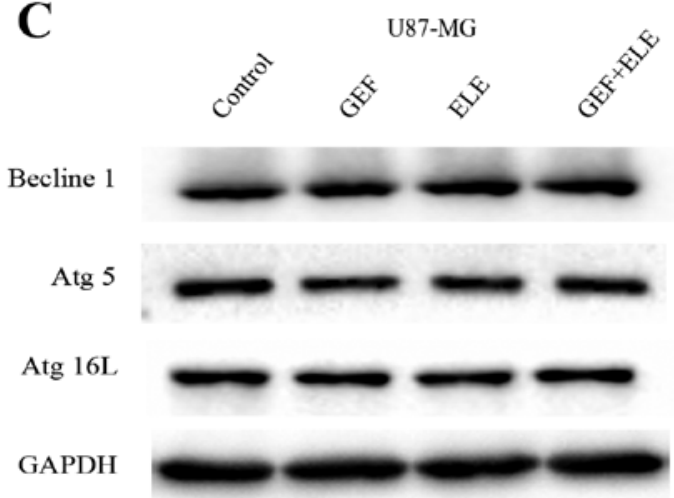

D
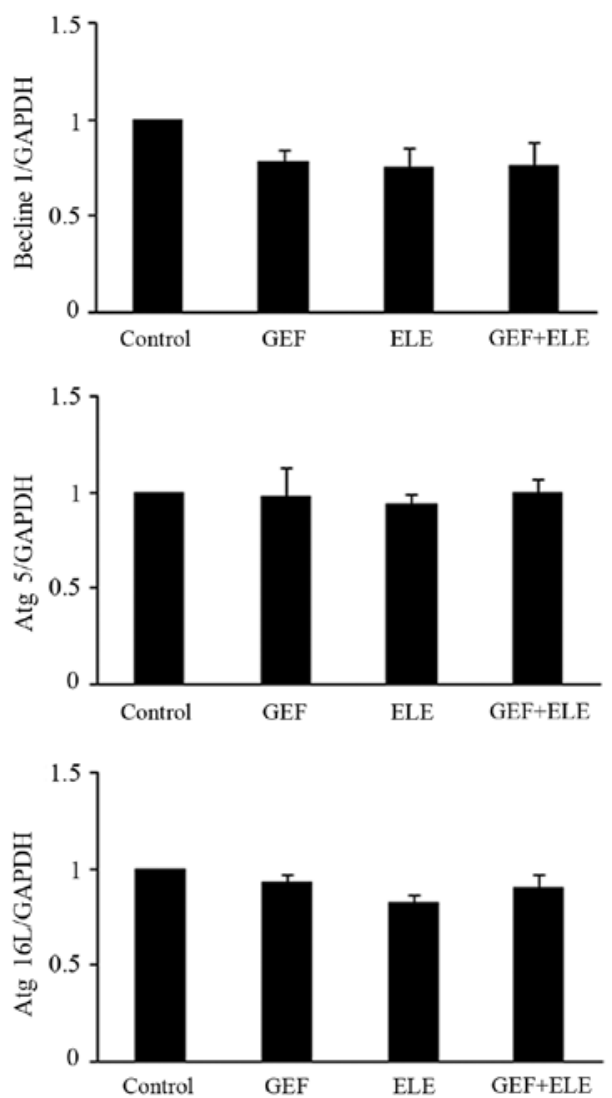

Figure 7. Effects of $\beta$-elemene and gefitinib combined on the expression of autophagy-related proteins. The human GBM cells U251 and U87-MG were treated with gefitinib $(30 \mu \mathrm{M})$ alone, $\beta$-elemene $(40 \mu \mathrm{g} / \mathrm{ml})$ alone or both for $24 \mathrm{~h}$. (A and C) The levels of Atg proteins were subjected to western blotting. GAPDH was used as loading control. (B and D) The levels of Becline 1, Atg5 and Atg16L were corrected for GAPDH. The results are representatives of three independent experiments. ${ }^{*} \mathrm{P}<0.05$, group treated with $\beta$-elemene vs. untreated group.

$30 \mu \mathrm{M}$ gefitinib, $40 \mu \mathrm{g} / \mathrm{ml} \beta$-elemene, and their combination in $\mathrm{U} 251$ for $24 \mathrm{~h}$, the localization of LC3 was evaluated by fluorescent microscopy. As shown in Fig. 5A and B, only a few LC3-positive puncta were observed in untreated control cells and single medication cells, while in the cells treated with the $\beta$-elemene and gefitinib, over $80 \%$ of cells showed LC3-positive puncta. The formation of autophagosomes was further confirmed by transmission electron microscopy (Fig. 5C). Upon treatment of combined $30 \mu \mathrm{M}$ gefitinib and $40 \mu \mathrm{g} / \mathrm{ml} \beta$-elemene in the U87-MG cells, many, double membrane enclosed vesicles containing engulfed organelles were observed in the cytoplasm (Fig. 5D). With the treatment of $30 \mu \mathrm{M}$ gefitinib, $40 \mu \mathrm{g} / \mathrm{ml} \beta$-elemene, and their combina- tion in human GBM cell lines U251 and U87-MG for $24 \mathrm{~h}$, levels of autophagy iconic protein LC3 (LC3-Iand LC3-II) were demonstrated by western blotting (Fig. 6A and C). In addition, level of LC3-II was more significantly increased in the combination group of gefitinib and $\beta$-elemene (Fig. 6B and D). These data indicated that the potentiation of $\beta$-elemene in gefitinib treatment not only resulted in apoptosis but also induced autophagy.

Effects of $\beta$-elemene and gefitinib combined on autophagy related proteins in GBM cells. There are many autophagyregulatory genes playing important roles in autophagy reaction, such as Becline 1, Atg5 and Atg16L. Human GBM cell lines 
$\mathrm{U} 251$ and U87-MG were treated with either $30 \mu \mathrm{M}$ gefitinib or $40 \mu \mathrm{g} / \mathrm{ml} \beta$-elemene, or co-treatment for $24 \mathrm{~h}$. Western blot analysis showed that the level of Becline 1 protein in U251 cells was upregulated (Fig. 7A and B), whereas the expression of Beclin 1 in U87-MG and other Atg proteins such as Atg5 and Atg16L were not significantly changed in U251 and U87-MG cells (Fig. 7C and D). A possibility is that $\beta$-elemene may affect autophagic flux rather than induce autophagy.

\section{Discussion}

EGFR signaling pathway involved in cancer development and prognosis opened avenues for targeted therapies, which made treatment more tumor-specific (27). However, EGFR-targeted therapeutics has been limited in clinical trials because of drug resistance and the severity of the various associated sideeffects of EGFR tyrosine kinase inhibitor gefitinib $(12,14)$. Comparatively, $\beta$-elemene, as a traditional anti-cancer Chinese herbal medicine, has been approved by the State Food and Drug Administration of China for the treatment of malignant effusion and some solid tumors. It also exhibited a wide range of anticancer effects with low toxicity and few side-effects in vitro and in vivo $(20,28)$. Numerous basic studies have concluded that $\beta$-elemene has strong antitumor activity on human GBM cell lines, as well as on rats and glioblastomabearing nude mice by inhibiting cell proliferation, inducing tumor cell apoptosis, and arresting cell cycle processes (29-31). Simultaneously, $\beta$-elemene is able to activate the p38 MAPK signaling pathway and inactivate RAF/MEK/ERK signaling pathway to induce cell cycle G0/G1 phase arrest of GBM cells (20). In addition, they are associated with therapeutic resistance of GBM cells. The data presented here provide evidence that the combination medication of $\beta$-elemene and gefitinib efficacy is obviously more effective than gefitinib alone.

As key downstream proteins of EGFR signaling pathway, AKT and ERK participated in many fundamental cellular processes such as increasing the ability of survival, migration and invasion of tumor cells (32). It has been reported that berberine induced senescence of GBM cells by downregulating the EGFR-MEK-ERK signaling pathway (33). Although current research related to $\beta$-elemene and EGFR is still not clear, some reports have shown that $\beta$-elemene could inhibit GBM cells growth by altering the activities of AKT and ERK $(26,34)$. The concentrations of $\beta$-elemene used in this study were consistent with or even lower than reported by others demonstrating substantial growth inhibition of different types of cancer cells. The $\mathrm{IC}_{50}$ value of U87-MG GBM cells showed stronger resistance than the U251 cells to either gefitinib or $\beta$-elemene treatment. The experimental group combining gefitinib and $\beta$-elemene significantly reduced the activities not only the phosphorylation of AKT and ERK but also the EGFR. The above indicated that $\beta$-elemene and gefitinib inhibited the proliferation and survival of GBM via inhibiting the activation of AKT and ERK which are related to the downstream EGFR signaling pathways, and $\beta$-elemene in combination with gefitinib produced a synergistic effect against human GBM cells.

Apoptosis is a special biological character of programmed cell death. Several findings have shown that $\beta$-elemene markedly promoted cisplatin-induced apoptotic cell death, decreased the expression level of the Bcl-2 protein, increased cytochrome $c$ release, activated poly ADP-ribose polymerase and caspase-3, -7 and -9 in prostate cancer cells. Concurrently, the apoptotic percentage of prostate cancer cells was increased by $\beta$-elemene in a dose- and time-dependent manner $(35,36)$. In addition, $\beta$-elemene could induce apoptosis and arrest non-small cell lung cancer cells at the G2/M phase (37). Furthermore, previous studies have demonstrated that $\beta$-elemene induced apoptosis in human glioma cells through inhibiting the molecular complex Hsp90/Raf-1 and upregulating Bax, Fas/FasL and downregulating Bcl-2 $(25,38)$. In the present study, we found that the changes in apoptosis related proteins are not obvious after the separate treatment of $\beta$-elemene and gefitinib. However, the combination treatment of $\beta$-elemene and gefitinib induced apoptosis in GBM cells through mitochondrial apoptotic pathway, this is also supported by evidence including the release of activated PARP and caspase-3.

Based on more comprehensive study of $\beta$-elemene in killing tumor cells especially research on the mechanism by which $\beta$-elemene induces autophagy of GBM cells, our experiments examined the activity of both apoptosis and autophagy in the human GBM cells subjected to combination drug therapy of $\beta$-elemene and gefitinib. Autophagy is another key cellular process known to promote occurrence of cell death. It is an intracellular degradation process in eukaryotic cells induced by stress, organelles within double membraned autophagosomes via degrading cytoplasmic components to maintain cell homeostasis $(39,40)$. $\beta$-Elemene is associated with occurrence of autophagy in other tumor cells. Several studies have suggested that $\beta$-elemene significantly induced the conversion of LC3-I into LC3-II as well as the formation of autolysosomes, indicating the activation of autophagy. The derivatives of $\beta$-elemene were able to suppress the proliferation of SGC-7901 and HeLa cells by inhibiting mTOR activity and inducing autophagy $(17,41)$. In the present study, a robust autophagy was observed among the cells treated with combination of $\beta$-elemene and gefitinib to enhance gefitinib induced apoptosis, which was verified by the increase of punctate LC3 and the morphologic changes. Western blotting showed that the combination of $\beta$-elemene and gefitinib indeed induced the conversion of LC3-II from LC3-I, and these specific changes of LC3 have been characterized as an autophagosomal marker in mammalian autophagy. Accumulated evidence suggested that the induction of autophagy is associated with the upregulation of certain Atg proteins. For example, Thyagarajan et al (42) reported that triterpene-induced autophagy is accompanied by the upregulation of Beclin 1 . Notably, neither $\beta$-elemene nor combination gefitinib and $\beta$-elemene induced autophagy with significantly alternating the levels of Atg proteins except for the expression level of the Beclin1 protein in our study. We speculate that it may be related to the type of tumor cells, malignant degree and concentration of specificity drug treatment. Another possibility is that $\beta$-elemene may affect autophagic flux rather than induce autophagy. Under the combined treatment of gefitinib and $\beta$-elemene, the activity of Beclin1 protein is significantly upregulated comparing with gefitinib monotherapy in the human GBM cells. 
Taken together, this study provides the first evidence that $\beta$-elemene could enhance the efficacy of gefitinib to inhibit the proliferation and survival of GBM cells along with downregulating the activity of EGFR, AKT and ERK. In addition, the antitumor effect of $\beta$-elemene could strengthen the ability of gefitinib to induce apoptosis of GBM cells. More importantly, the EGFR signaling pathway was inhibited by the combination of $\beta$-elemene and gefitinib, which not only led to activation of a protective autophagy but also significantly enhanced the apoptosis-inducing ability. This combination treatment scheme might be a new efficacious strategy for the treatment of primary brain tumors in the future.

\section{Acknowledgements}

The present study was supported by the National Science Foundation of China (no. 81202964) and the Liaoning Province Natural Science Foundation of China (no. 2013023043). We also thank all our colleagues in our research group for their generous support.

\section{References}

1. Louis DN, Ohgaki H, Wiestler OD, Cavenee WK, Burger PC, Jouvet A, Scheithauer BW and Kleihues P: The 2007 WHO classification of tumours of the central nervous system. Acta Neuropathol 114: 97-109, 2007.

2. Eimer S, Belaud-Rotureau M-A, Airiau K, Jeanneteau M, Laharanne E, Véron N, Vital A, Loiseau H, Merlio JP and Belloc F: Autophagy inhibition cooperates with erlotinib to induce glioblastoma cell death. Cancer Biol Ther 11: 1017-1027, 2011.

3. Gudinaviciene I, Pranys D and Juozaityte E: Impact of morphology and biology on the prognosis of patients with gliomas. Medicina (Kaunas) 40: 112-120, 2004.

4. Stupp R, Mason WP, van den Bent MJ, Weller M, Fisher B, Taphoorn MJ, Belanger K, Brandes AA, Marosi C, Bogdahn U, et al; European Organisation for Research and Treatment of Cancer Brain Tumor and Radiotherapy Groups; National Cancer Institute of Canada Clinical Trials Group: Radiotherapy plus concomitant and adjuvant temozolomide for glioblastoma. $\mathrm{N}$ Engl J Med 352: 987-996, 2005.

5. Fine HA, Dear KB, Loeffler JS, Black PM and Canellos GP: Meta-analysis of radiation therapy with and without adjuvant chemotherapy for malignant gliomas in adults. Cancer 71: 2585-2597, 1993.

6. Appert-Collin A, Hubert P, Crémel G and Bennasroune A: Role of ErbB receptors in cancer cell migration and invasion. Front Pharmacol 6: 283, 2015.

7. Lund-Johansen M, Bjerkvig R, Humphrey PA, Bigner SH, Bigner DD and Laerum OD: Effect of epidermal growth factor on glioma cell growth, migration, and invasion in vitro. Cancer Res 50: 6039-6044, 1990

8. Nishikawa R, Ji XD, Harmon RC, Lazar CS, Gill GN, Cavenee WK and Huang HJ: A mutant epidermal growth factor receptor common in human glioma confers enhanced tumorigenicity. Proc Natl Acad Sci USA 91: 7727-7731, 1994.

9. Li B, Chang CM, Yuan M, McKenna WG and Shu HK: Resistance to small molecule inhibitors of epidermal growth factor receptor in malignant gliomas. Cancer Res 63: 7443-7450, 2003.

10. Chang CY, Kuan YH, Ou YC, Li JR, Wu CC, Pan PH, Chen WY, Huang HY and Chen CJ: Autophagy contributes to gefitinibinduced glioma cell growth inhibition. Exp Cell Res 327: 102-112, 2014

11. Chang CY, Shen CC, Su HL and Chen CJ: Gefitinib induces apoptosis in human glioma cells by targeting Bad phosphorylation. J Neurooncol 105: 507-522, 2011.

12. Rich JN, Reardon DA, Peery T, Dowell JM, Quinn JA, Penne KL, Wikstrand CJ, Van Duyn LB, Dancey JE, McLendon RE, et al: Phase II trial of gefitinib in recurrent glioblastoma. J Clin Oncol 22: $133-142,2004$.
13. Agarwal S, Sane R, Gallardo JL, Ohlfest JR and Elmquist WF: Distribution of gefitinib to the brain is limited by P-glycoprotein (ABCB1) and breast cancer resistance protein (ABCG2)mediated active efflux. J Pharmacol Exp Ther 334: 147-155, 2010.

14. Zhao L, Yang G, Shi Y, Su C and Chang J: Co-delivery of Gefitinib and chloroquine by chitosan nanoparticles for overcoming the drug acquired resistance. J Nanobiotechnology 13: $57,2015$.

15. Zou ZZ, Nie PP, Li YW, Hou BX, Rui-Li, Shi XP, Ma ZK, Han BW and Luo XY: Synergistic induction of apoptosis by salinomycin and gefitinib through lysosomal and mitochondrial dependent pathway overcomes gefitinib resistance in colorectal cancer. Oncotarget: Oct 5, 2015 (Epub ahead of print). doi: 10.18632/oncotarget.5628.

16. Wang G, Li X, Huang F, Zhao J, Ding H, Cunningham C, Coad JE, Flynn DC, Reed E and Li QQ: Antitumor effect of beta-elemene in non-small-cell lung cancer cells is mediated via induction of cell cycle arrest and apoptotic cell death. Cell Mol Life Sci 62: 881-893, 2005.

17. Ding XF, Shen M, Xu LY, Dong JH and Chen G: 13,14-bis(cis3,5-dimethyl-1-piperazinyl)- $\beta$-elemene, a novel $\beta$-elemene derivative, shows potent antitumor activities via inhibition of mTOR in human breast cancer cells. Oncol Lett 5: 1554-1558, 2013.

18. Yu Z, Wang R, Xu L, Xie S, Dong J and Jing Y: $\beta$-Elemene piperazine derivatives induce apoptosis in human leukemia cells through downregulation of c-FLIP and generation of ROS. PLoS One 6: e15843, 2011

19. Li X, Wang G, Zhao J, Ding H, Cunningham C, Chen F, Flynn DC, Reed E and Li QQ: Antiproliferative effect of betaelemene in chemoresistant ovarian carcinoma cells is mediated through arrest of the cell cycle at the G2-M phase. Cell Mol Life Sci 62: 894-904, 2005.

20. Yao YQ, Ding X, Jia YC, Huang CX, Wang YZ and Xu YH: Anti-tumor effect of beta-elemene in glioblastoma cells depends on p38 MAPK activation. Cancer Lett 264: 127-134, 2008.

21. Wu XS, Xie T, Lin J, Fan HZ, Huang-Fu HJ, Ni LF and Yan HF: An investigation of the ability of elemene to pass through the blood-brain barrier and its effect on brain carcinomas. J Pharm Pharmacol 61: 1653-1656, 2009.

22. Alvarez-García V, González A, Alonso-González C, MartínezCampa C and Cos S: Regulation of vascular endothelial growth factor by melatonin in human breast cancer cells. J Pineal Res 54: 373-380, 2013.

23. Lu X, Wang Y, Luo H, Qiu W, Han H, Chen X and Yang L: $\beta$-elemene inhibits the proliferation of T24 bladder carcinoma cells through upregulation of the expression of Smad4. Mol Med Rep 7: 513-518, 2013.

24. Liu J, Zhang Y, Qu J, Xu L, Hou K, Zhang J, Qu X and Liu Y: $\beta$-Elemene-induced autophagy protects human gastric cancer cells from undergoing apoptosis. BMC Cancer 11: 183, 2011.

25. Zhao YS, Zhu TZ, Chen YW, Yao YQ, Wu CM, Wei ZQ, Wang W and Xu YH: B-elemene inhibits Hsp90/Raf-1 molecular complex inducing apoptosis of glioblastoma cells. J Neurooncol 107: 307-314, 2012.

26. Liu S, Zhou L, Zhao Y and Yuan Y: $\beta$-elemene enhances both radiosensitivity and chemosensitivity of glioblastoma cells through the inhibition of the ATM signaling pathway. Oncol Rep 34: 943-951, 2015

27. Zhao Q, Kretschmer N, Bauer R and Efferth T: Shikonin and its derivatives inhibit the epidermal growth factor receptor signaling and synergistically kill glioblastoma cells in combination with erlotinib. International journal of cancer. Int J Cancer 137: 1446-1456, 2015

28. Zhu T, Li X, Luo L, Wang X, Li Z, Xie P, Gao X, Song Z, Su J and Liang G: Reversion of malignant phenotypes of human glioblastoma cells by $\beta$-elemene through $\beta$-catenin-mediated regulation of stemness-, differentiation- and epithelial-to-mesenchymal transition-related molecules. J Transl Med 13: 356, 2015.

29. Sun Y, Liu G, Zhang Y, Zhu H, Ren Y and Shen YM: Synthesis and in vitro anti-proliferative activity of beta-elemene monosubstituted derivatives in HeLa cells mediated through arrest of cell cycle at the G1 phase. Bioorg Med Chem 17: 1118-1124, 2009.

30. Yu Z, Wang R, Xu L, Dong J and Jing Y: N-(beta-Elemene-13-yl) tryptophan methyl ester induces apoptosis in human leukemia cells and synergizes with arsenic trioxide through a hydrogen peroxide dependent pathway. Cancer Lett 269: 165-173, 2008.

31. Yao YQ, Xu YH, Lu J, Zhou HY and Wang YZ: Effect of p38 MAPK on elemene-induced cell cycle arrest in C6 glioblastoma cells. Zhonghua Yi Xue Za Zhi 88: 56-58, 2008 (In Chinese). 
32. Zhou J, Du T, Li B, Rong Y, Verkhratsky A and Peng L: Crosstalk between MAPK/ERK and PI3K/AKT signal pathways during brain ischemia/reperfusion. ASN Neuro 7: 7,2015.

33. Liu Q, Xu X, Zhao M, Wei Z, Li X, Zhang X, Liu Z, Gong Y and Shao C: Berberine induces senescence of human glioblastoma cells by downregulating the EGFR-MEK-ERK signaling pathway. Mol Cancer Ther 14: 355-363, 2015.

34. Zhan YH, Liu J, Qu XJ, Hou KZ, Wang KF, Liu YP and Wu B: $\beta$-Elemene induces apoptosis in human renal-cell carcinoma 786-0 cells through inhibition of MAPK/ERK and PI3K/ Akt/ mTOR signalling pathways. Asian Pac J Cancer Prev 13: 2739-2744, 2012.

35. Li QQ, Wang G, Reed E, Huang L and Cuff CF: Evaluation of cisplatin in combination with $\beta$-elemene as a regimen for prostate cancer chemotherapy. Basic Clin Pharmacol Toxicol 107: 868-876, 2010.

36. Li QQ, Wang G, Huang F, Banda M and Reed E: Antineoplastic effect of beta-elemene on prostate cancer cells and other types of solid tumour cells. J Pharm Pharmacol 62: 1018-1027, 2010.

37. Wang CF, Fan L, Tian M, Qi XS, Liu JX, Feng JB, Du SS, Su X and Wang YY: Radiosensitizing effect of schinifoline from Zanthoxylum schinifolium Sieb et Zucc on human non-small cell lung cancer A549 cells: A preliminary in vitro investigation. Molecules 19: 20128-20138, 2014.
38. Li CL, Chang L, Guo L, Zhao D, Liu HB, Wang QS, Zhang P, Du WZ, Liu X, Zhang HT, et al: $\beta$-elemene induces caspasedependent apoptosis in human glioma cells in vitro through the upregulation of Bax and Fas/ FasL and downregulation of Bcl-2. Asian Pac J Cancer Prev 15: 10407-10412, 2014.

39. Shi JM, Bai LL, Zhang DM, Yiu A, Yin ZQ, Han WL, Liu JS, Li Y, Fu DY and Ye WC: Saxifragifolin D induces the interplay between apoptosis and autophagy in breast cancer cells through ROS-dependent endoplasmic reticulum stress. Biochem Pharmacol 85: 913-926, 2013.

40. Maiuri MC, Zalckvar E, Kimchi A and Kroemer G: Self-eating and self-killing: Crosstalk between autophagy and apoptosis. Nat Rev Mol Cell Biol 8: 741-752, 2007.

41. Guan C, Liu W, Yue Y, Jin H, Wang X and Wang XJ: Inhibitory effect of $\beta$-elemene on human breast cancer cells. Int J Clin Exp Pathol 7: 3948-3956, 2014.

42. Thyagarajan A, Jedinak A, Nguyen H, Terry C, Baldridge LA, Jiang J and Sliva D: Triterpenes from Ganoderma Lucidum induce autophagy in colon cancer through the inhibition of p38 mitogen-activated kinase (p38 MAPK). Nutr Cancer 62: 630-640, 2010. 